\title{
Application of Expert System with Smartphone-based Certainty Factor Method for Hypertension Risk Detection
}

\author{
Dodon Yendri ${ }^{1}$, Derisma ${ }^{2}$, Desta Yolanda ${ }^{3}$, Sabrun Jamil $^{4}$ \\ Computer Engineering Department \\ Andalas University, Padang, Indonesia
}

\begin{abstract}
Hypertension is a factor health problem with a high prevalence in Indonesia. The total amount of hypertension nationwide is $34.11 \%$. There are only $1 / 2$ were diagnosed, and the remaining $1 / 2$ are undiagnosed. Certainty factor was needed to prove the certain or not of a fact in a metric form, and it commonly was used in expert systems. This method was perfect for diagnosing something uncertain. This research aimed to build a smartphone-based hypertension risk detection system. This system was built by MPX5500DP pressure sensor components that served for blood pressure measurement, Bluetooth module HC-05 as microcontroller data transmission, Arduino Uno as sensor data processing, and Smartphone as hypertension risk detection interface and database access. Measuring blood pressure on the user's right or left arm was used to test the system. Then the data was sent to the smartphone to be classified and processed by using the certainty factor method implanted in the android smartphone to detect the risk of hypertension and then followed by the selection of symptoms and risk factors of hypertension according to previous experience. The results showed that the success rate of the system in detecting the risk of hypertension was $100 \%$, the mean error of the systolic value of

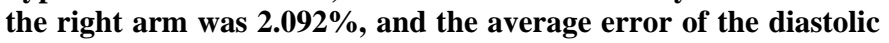
value of the right arm was $2.977 \%$, while the average error of the systolic value of the left arm. $1.944 \%$ and the mean error of the left arm diastolic value was $2.800 \%$.
\end{abstract}

Keywords-Hypertension; certainty factor; blood pressure; mpx5500dp

\section{INTRODUCTION}

Based on the 2018 Basic Health Research, the national hypertension prevalence is $34.11 \%$. In the percentage of $34.11 \%$, half of the people who have hypertension have been diagnosed, and most of them undiagnosed. Data shows that only $54.4 \%$ of people diagnosed with high blood pressure take hypertension medication [1]. This explanation tells that most hypertension sufferers are unaware that they are suffering from hypertension [2],[3], [4] and are not getting treatment [4], [5]. Hypertension is one of the big problems in the public health field [6], especially in Indonesia. That expressed because hypertension is a health problem with a high prevalence [3], [7], [8]. The Estimated one in three people will suffer from hypertension in 2025 [4].

Hypertension is a condition where the systolic blood pressure value is $\geq 140 \mathrm{mmHg}$, or the diastolic value is $\geq 90$ $\mathrm{mmHg}$ [9]. The increase of blood pressure in a long time can cause kidneys, heart, and brain damage until stroke if it is not detected early [10] and does not receive adequate treatment [11], [12]. A sphygmomanometer, a tool in the medical world, is used to check blood pressure [13] in humans and, it also a medium that can detect hypertension. The Sphygmomanometer consists of an analog sphygmomanometer and a digital Sphygmomanometer [14]. Analog Sphygmomanometer works manually means to be able to know blood pressure precisely depend on the user's expertise [15]. It works using Korotkoff methods in determining the patient's systolic and diastolic through coronary sound from the stethoscope. While digital A sphygmomanometer works based on oscillometry methods in which to determine systolic and diastolic patients use pressure sensors as transducers that will detect blood pressure and oscillation signal changes due to heart rate [4], [16].

There are many mobile health apps (mHealth apps) available in the market currently. This app is designed to facilitate a wide range of health issues and concern that is intended for use outside of the clinic. The review study also found that researchers and publishers of mHealth focused more on individual preventative diseases such as selfmanagement for diabetes [17], [18], [19], gout [20], chronic obstructive pulmonary disease [21], bipolar disorder [22] and bowel disease [ 23], stroke [24], [25], heart disease [26] and flu [27].

Fitriani et 'al research [28] developed a mobile application for early prediction of diabetes type 2 and hypertension based on the factor data individual risk by integrating iForest, SMOTETomek, and ensemble learning. iForest was used to detect and remove outlier data from the dataset. Meanwhile SMOTETomek was used to balance unbalanced datasets and ensemble learning was applied to predict disease. This study collected risk factor data and sent it to a remote server for diagnosis with the proposed prediction model. The prediction results were sent back to the car application. The weakness of this research was the process of sending data back and forth to get action to prevent individual risk.

Furthermore, Egejuru et 'al [29] developed a cellular-based hypertension risk monitoring system. BP_HRM System developed for users can access the system from distant locations easily. The mobile application was designed using an integrated modeling language and implemented using the Adaptive Neuro-Fuzzy Inference System (ANFIS) and Extensible Mark-Up Language methods with the Java 
programming language for layout and mobile content. JavaScript Object Notation was used to implement the system's data storage and retrieval mechanisms. This study had not provided information about the symptoms and factors that caused hypertension.

Based on previous research, we have carried out developmental research in addition to classifying hypertension as well as knowing the symptoms and factors that cause hypertension and the level of risk that will occur.

\section{COMMON FACTORS AND SYMPTOMS OF HYPERTENSION}

Hypertension is the pressure that pushes a wall of the arteries when the blood pumps into the arteries [30]. Systolic pressure or high blood pressure is given to the walls of the arteries when the heart contracts, whereas diastolic pressure or low blood pressure, the pressure given to the arteries when the heart relaxes. Blood pressure is generally measured in millimeters of mercury $(\mathrm{mmHg})[31]$.

Hypertension referred to as "the silent killer" [32], [33]. Generally, hypertension is asymptomatic [34]. Most people don't feel anything, even though their blood pressure is not normal [18]. It can continue for many years until the sufferer (who does not feel suffering) falls into an emergency and even has heart disease, sexual dysfunction, stroke, or damaged kidneys [35]. Based on the case, some hypertension sufferers do not specific hypertension symptoms, they only get headaches, impaired vision, restlessness, dizziness, fatigue, pain in the chest, and heavy feeling on the nape [36].

Hypertension generally causes the sufferer's unhealthy behavior. Some factors unhealthy behaviors can cause hypertension [8], [37]:

1) Smoking: Smoking increases the heart rate [37]. Therefore the muscles - heart muscles need a lot of oxygen. Smoking habits of hypertension sufferers will increase the risk of damage to arterial blood vessels.

2) Lack of physical activity: Exercise can help stabilize blood pressure[38], and it is beneficial for sufferer's mild hypertension. Moreover, aerobic exercise can drop blood pressure, although the weight has not dropped.

3) Excessive salt consumption: Salt causes a build-up of fluid in the body because it collects fluid inside the cell. It can cause the volume of blood pressure to increase [39]. The people who consume 3.5 grams or less salt had lower blood pressure than the community that consumes about 9-12 grams [40].

4) Excessive alcohol consumption: The effect of alcohol can increase blood pressure. Several studies showed a relationship between blood pressure and alcohol intake. The American Heart Association recommends limiting alcohol intake in order to avoid developing hypertension. Women should have no more than 1 drink per day and no more than 2 drinks per day for men [41].

5) Psychosocial and stress: Stress or mental tension (depressed, moody, angry, revenge, fear, guilt) can stimulate the kidney glands to release adrenaline hormones and spur the beat heart is faster and stronger than usual. It can cause blood pressure to increase [42]. If people get stress for a long time, their body will occur pathological changes and organic abnormalities. The Symptoms can be hypertension or stomach ulcers. Table 1 shows the common factors and symptoms of hypertension.

TABLE I. SYMPTOMS AND RISK FACTORS FOR HYPERTENSION [18]

\begin{tabular}{|c|c|c|}
\hline No. & Symptom Name & Value $(\mathrm{CF})$ \\
\hline \multicolumn{3}{|c|}{ Physical Complaints } \\
\hline 1. & Headache & \multirow{8}{*}{0.6} \\
\hline 2. & Dizzy & \\
\hline 3. & Tired easily & \\
\hline 4. & Restless & \\
\hline 5. & Pain in the chest & \\
\hline 6. & Interrupted vision & \\
\hline 7. & Heart palpitations & \\
\hline 8. & Nape weight & \\
\hline \multicolumn{3}{|c|}{ Personal History of Hypertension } \\
\hline 9. & $\begin{array}{l}\text { In the Treatment Period for Hypertension (anti- } \\
\text { hypertensive drugs) }\end{array}$ & 0.6 \\
\hline \multicolumn{3}{|c|}{ History of Hard Disease } \\
\hline 10. & Heart & \multirow{4}{*}{0.8} \\
\hline 11. & Brain & \\
\hline 12. & Eyes & \\
\hline 13. & Diabetes Mellitus & \\
\hline 14. & Kidney & \\
\hline \multicolumn{3}{|c|}{ Social History } \\
\hline 15. & Doing Strenuous Activities & \multirow{8}{*}{0.4} \\
\hline 16. & Moker & \\
\hline 17. & Consuming alcohol & \\
\hline 18. & Consumption of Excessive Salt & \\
\hline 19. & consuming fatty foods & \\
\hline 20. & consuming coffee & \\
\hline 21. & Stress & \\
\hline 22. & Lack of exercise & \\
\hline \multicolumn{2}{|c|}{ Family History of Hypertension } & 0.2 \\
\hline
\end{tabular}

\section{ClASSIFICATION OF HYPERTENSION}

Hypertension has two types Based on the cause. They are Essential hypertension (primary) and Secondary hypertension [43], [44]. Essential hypertension (primary) is a type of hypertension that often occurs in hypertension cases about 95 percent. This type is related to lifestyle factors such as lack of movement (inactivity) and diet [45]. Meanwhile, secondary hypertension, type hypertension seldom in hypertension cases. It is related to medical conditions, such as heart disease or reactions medications.

According to the Sevent's Report of the Joint National Committee on Detection, Evaluation and Treatment of High Blood Pressure (JNC7) 2003 [41], [46], hypertension classified into four categories in Table 2. 
TABLE II. CLASSIFICATION OF HYPERTENSION ACCORDING TO JNC7 2003 [41]

\begin{tabular}{|l|l|l|l|}
\hline Category & TDS $(\mathbf{m m H g})$ & & TDD $(\mathbf{m m H g})$ \\
\hline Normal & $<120$ & and & $<80$ \\
\hline Prehypertension & $120-139$ & or & $80-89$ \\
\hline Hypertension stage 1 & $140-159$ & or & $90-99$ \\
\hline Hypertension stage 2 & $\geq 160$ & or & $\geq 100$ \\
\hline
\end{tabular}

\section{CERTAinty FACTOR}

The certainty factor method is used in facing a problem that the answer is uncertain. This uncertainty is a probability. This method was introduced in the 1970 s by Short-life Buchanan. Buchanan used this method when he diagnosed and therapy meningitis and blood infections (Wikipedia). The development team of this method noted that doctors often analyzed existing information with phrases such as almost certain.

This method was almost similar to fuzzy logic because uncertainty is represented by the degree of trust. The difference is in the fuzzy logic's rules [47]. The fuzzy logic does not have a confidence value if it calculates the premise more than one. The fuzzy logic's calculation can see the lower value in AND operator and the highest value in the OR operator. It is different with a certainty factor [48]. It has trust value on each premise and shows the measure of certainty of a fact or rule.

$\mathrm{CF}[\mathrm{h}, \mathrm{e}]=\mathrm{MB}[\mathrm{h}, \mathrm{e}]-\mathrm{MD}[\mathrm{h}, \mathrm{e}]$

Description:

$\mathrm{CF}[\mathrm{h}, \mathrm{e}]=$ Certainty factor

$\mathrm{MB}[\mathrm{h}, \mathrm{e}]=$ Measure of belief, a measure of belief or confidence level of the hypothesis (h), if given evidence (e) between 0 and 1 .

$\mathrm{MD}[\mathrm{h}, \mathrm{e}]=$ Measure of disbelief, a measure of disbelief, or confidence level of the hypothesis (h), if given evidence (e) between 0 and 1 .

There are several combinations of certainty factor against certain premises, namely:

1) Certainty factor with one premise.

$\mathrm{CF}[\mathrm{h}, \mathrm{e}]=\mathrm{CF}[\mathrm{e}]^{*} \mathrm{CF}[$ rule $]=\mathrm{CF}[$ user $] * \mathrm{CF}[$ pakar $]$

2) Certainty factor with more than one premise.

$\mathrm{CF}[\mathrm{A} \wedge \mathrm{B}]=\operatorname{Min}(\mathrm{CF}[\mathrm{a}], \mathrm{CF}[\mathrm{b}]) * \mathrm{CF}[$ rule $]$

$\mathrm{CF}[\mathrm{A} \vee \mathrm{B}]=\operatorname{Max}(\mathrm{CF}[\mathrm{a}], \mathrm{CF}[\mathrm{b}]) * \mathrm{CF}[$ rule $]$

3) Certainty factor with a similar conclusion.

CFcombined $[\mathrm{CF} 1, \mathrm{CF} 2]=\mathrm{CF} 1+\mathrm{CF} 2 *(1-\mathrm{CF} 1)$

This method has advantages such as suitable for measuring something certain or uncertain in diagnosing a disease. In addition, this method only applied one calculation, and it reached out two data therefore its accuracy was maintained.
The planning of the test was needed by getting the best result of the test, both hardware and software testing. Table 3 shows the hardware test design, and Table 4 shows the software design.

TABLE III. HARDWARE TEST DESIGN

\begin{tabular}{|l|l|l|l|}
\hline No & Hardware & Test Design & Destination \\
\hline & blood & $\begin{array}{l}\text { Get error values for } \\
\text { measuring tools and } \\
\text { digital }\end{array}$ & $\begin{array}{l}\text { Get a comparison of the } \\
\text { measurement results of } \\
\text { tools and digital } \\
\text { sphygmomanometers. }\end{array}$ \\
\hline
\end{tabular}

TABLE IV. SOFtware TeSt DESIGN

\begin{tabular}{|l|l|l|l|}
\hline No & Hardware & Test Design & Destination \\
\hline 1 & $\begin{array}{l}\text { Mobile } \\
\text { Application }\end{array}$ & $\begin{array}{l}\text { Testing the detection of } \\
\text { hypertension risk was } \\
\text { successfully obtained from } \\
\text { the data obtained }\end{array}$ & $\begin{array}{l}\text { To find out the results of } \\
\text { detecting the user's } \\
\text { hypertension risk } \\
\text { successfully obtained }\end{array}$ \\
\hline 2 & $\begin{array}{l}\text { Certainty } \\
\text { factor } \\
\text { method }\end{array}$ & $\begin{array}{l}\text { Testing the obtained } \\
\text { hypertension risk value }\end{array}$ & $\begin{array}{l}\text { To determine the risk } \\
\text { value of hypertension } \\
\text { obtained }\end{array}$ \\
\hline
\end{tabular}

\section{ANALYSIS OF RESUlT}

The expert system implementation shows in Fig. 1 using a blood pressure gauge that is Arduino Uno, MPX5500DP Pressure Sensor, Bluetooth HC-05 module, Arm cuff is an airbag that circles on the user's arm, and Android Smartphone.

1) MPX5500DP Pressure sensor testing: This test found out the extended function of the MPX5500DP sensor measuring the user's blood pressure. Testing was conducted by connecting sensors, cuffs, and analog Sphygmomanometers to a hose that has three ends. Once the three components had connected, the air pumped into the cuff until it gets a pressure value to be tested. It consists of the systolic value(s) and the diastolic value (d) read by the embedded software. Once the pressure value is obtained, then it is sent to the app via a serial communication function between Arduino and the android app via Bluetooth. The results of pressure measurements using the system shown in Fig. 2:

Furthermore based on the pressure value obtained, then the value is classified and displayed on the smartphone as seen in Fig. 3.

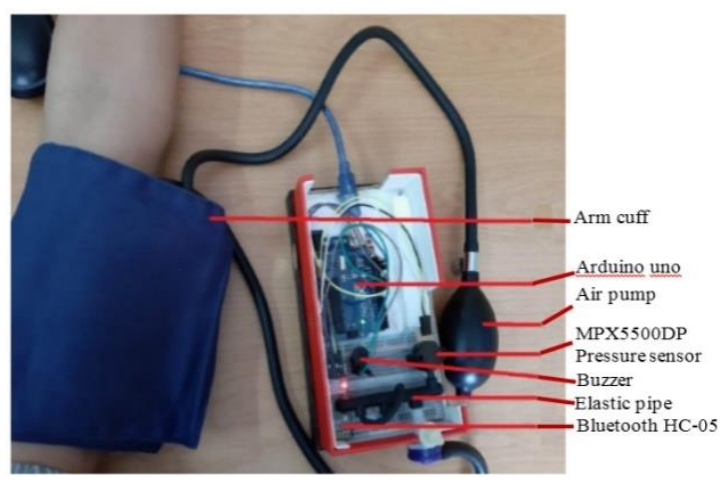

Fig. 1. Blood Pressure Gauge. 


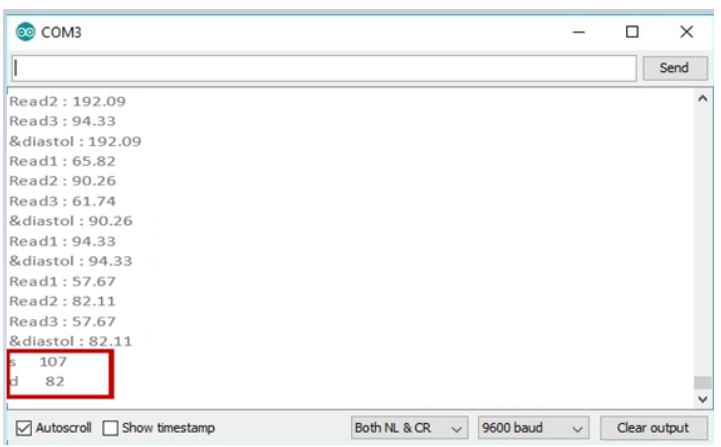

Fig. 2. Measurement of Blood Pressure by the System.

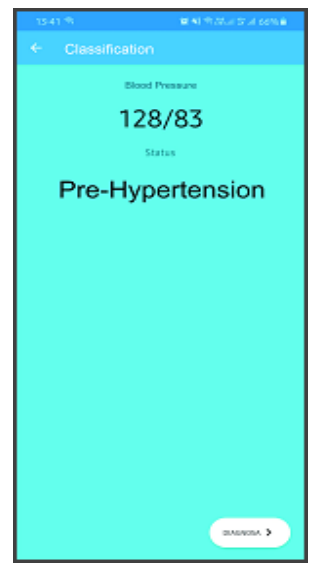

Fig. 3. Pressure Classification Page.

The determining of the system accuracy was conducted by comparing medical devices that had the same function as analog Sphygmomanometers. First, the cuffs were attached to the user's arm, and then performed air pumping through an elastic balloon into the cuff until the air pressure on the cuff reached $\geq 180 \mathrm{mmHg}$, then the air was released slowly by the mechanic's tool. It took systolic and diastolic values when the pressure drops continuously. Systolic value took if the tool would reach out the first spike in the pressure value, and Diastolic value took the last spike in pressure. After the data obtained, it is sent to the app via Bluetooth, and it is transferred to the smartphone to be classified and processed using the certainty factor method. Furthermore, the same way did test with analog Sphygmomanometers.

Fig. 4 shows the results of a blood pressure measurement from 20 tests using the MPX5500DP pressure sensor and analog Sphygmomanometer.

From the graph in Fig. 7, it can be seen that the measurement results using the MPX5500DP pressure sensor are almost the same as the measurements using an analog Sphygmomanometer.

2) Blood pressure testing on right arm and left arm: This test is to find out the system extent implemented to measure the user's blood pressure. This test is performed on the right arm and left arm user. Fig. 5 and Fig. 6 show the comparison of measurement test results of blood pressure on the right arm and left arm from 10 different users using mpx5500DP sensors and analog Sphygmomanometers.

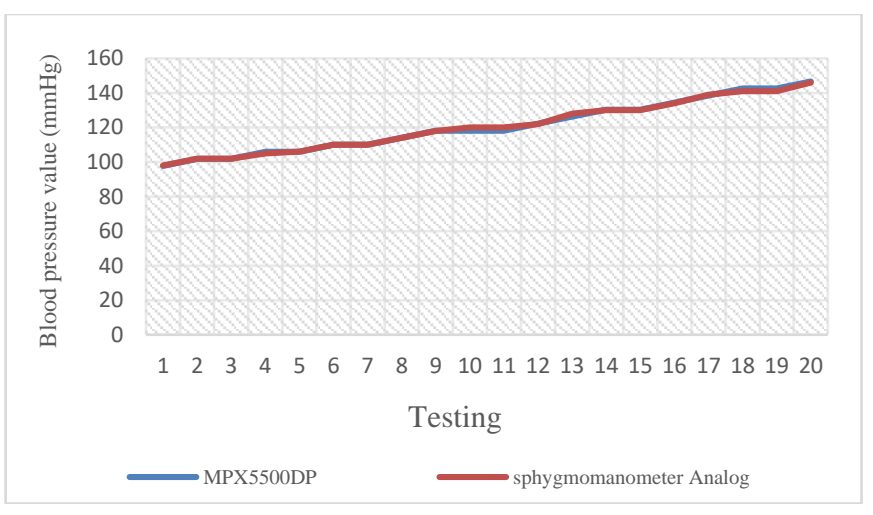

Fig. 4. Blood Pressure Comparison.

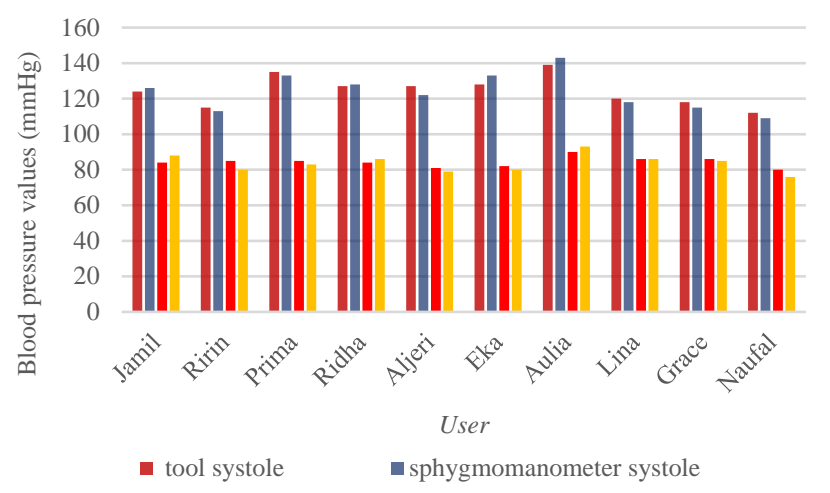

Fig. 5. Blood Pressure Measurement Testing Graph on Right Arm.

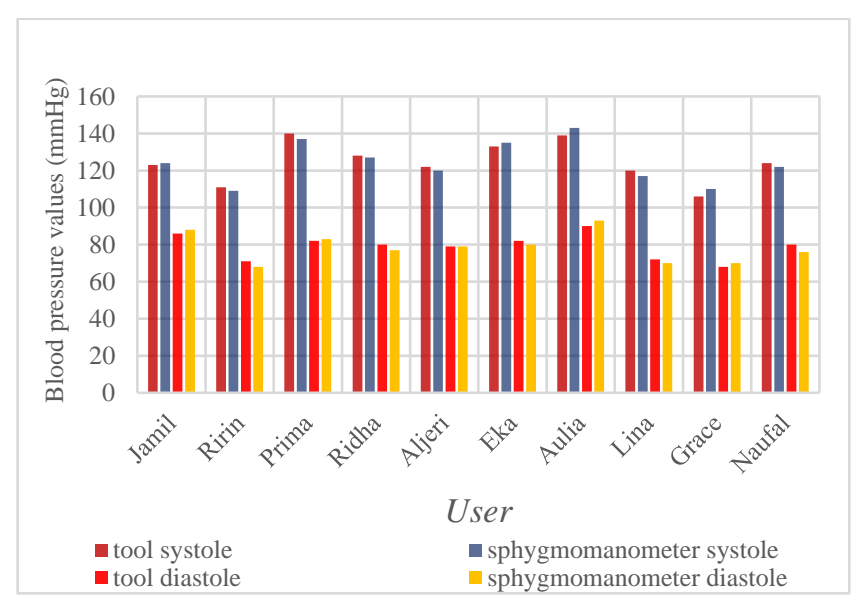

Fig. 6. Blood Pressure Measurement Testing Graph on Left Arm.

Based on a graph test performed shows in Fig. 5 and Fig. 6 states that testing using the MPX5500DP sensor and analog Sphygmomanometer provides almost the same results. From the data of blood pressure measurement tests on both arms, the calculation of systolic and diastolic error values of both of them was calculated using the formula:

- Average Right Arm Systolic Value Error =

Number of Right Arm Systolic Error Values

Number of Experiments

$$
=\frac{20.927}{10} \times 100 \%=2.097 \%
$$


- $\quad$ Average Right Arm Diastolic Value Error =

Number of Right Arm Diastolic Error Values

$$
\begin{aligned}
& \text { Number of Experiments } \\
& \qquad=\frac{29.778}{10} \times 100 \%=2.977 \%
\end{aligned}
$$

- Average Left Arm Systolic Value Error =

Number of Left Arm Systolic Error Values

$$
\begin{aligned}
& \text { Number of Experiments } \\
& \qquad=\frac{19.441}{10} \times 100 \%=1.944 \%
\end{aligned}
$$

- Average Left Arm Diastolic Value Error =

$\frac{\text { Number of Diastolic Tool Error Values }}{\text { Number of Experiments }}=\frac{28.009}{10} \times 100 \%$
$=2.800 \%$

From the calculation of the equation above, there was a significant difference in the average value of systolic and diastolic errors in both arms. The difference between them could be caused by several vascular abnormalities in both of a person's arms. The greatest possibility was a blockage of the walls of arterial blood vessels, either due to fat or other plaque, on arms with higher blood pressure. The difference in the average error value of both arms shows the graph in Fig. 7.

3) Accuracy testing: Accuracy testing is performed to determine the capabilities of expert systems embedded in the software using the Certainty factor method. This test shows that the application of the certainty factor method could calculate the hypertension risk for the users based on the symptoms and risk factors of hypertension chose by them.

The Table 5 shows the results of accuracy tests conducted based on one of the system tests as a whole.

Based on Table 3 of the test results above, the percentage value of Hypertension risk was derived from the equation of the Certainty factor method embedded in hypertension risk detection software. The equation of the certainty factor method would process the certainty factor $(\mathrm{CF})$ value according to the symptoms and hypertension factors selected by the user. This is a manual calculation of certainty factor equations to see the accuracy of the methods embedded in the software:

$$
\begin{aligned}
& \mathrm{CFA}=\mathrm{CF} 1+\mathrm{CF} 2 *(1-\mathrm{CF} 1) \\
& \mathrm{CFA}=0,6+0.4 *(1-0.6) \\
& \mathrm{CFA}=0,6+0.4(0.4) \\
& \mathrm{CFA}=0,6+0.16 \\
& \mathrm{CFA}=0,76
\end{aligned}
$$

Percentage $\mathrm{CF}=0.76 * 100 \%=76 \%$
CF1 and CF2 values refer to Table 2. The results of the calculation of hypertension risk with certainty factor method manually according to the results of detection using the certainty factor method embedded into hypertension risk detection software.

4) Early detection testing of overall hypertension risk: This test was conducted to determine whether an Androidbased expert system application has an embedded knowledge base on detecting hypertension risk that supports the system using the Certainty Factor method. The certainty factor method could show a measure of certainty based on facts or rules. That factor method showed the results in the numbers form. The use of blood pressure measurement data had classified an application implanted in a smartphone, then the system processes it by implementing equations (5). The results of the process were stored in Firebase and displayed on android smartphones in real-time. Table 6 shows the results of blood pressure classification testing and early detection of Hypertension Risk levels based on symptoms and factors displayed on smartphones from10 test cases using the Certainty Factor method.

From Table 4, it can be explained that the system can

\begin{tabular}{|c|c|c|c|c|c|}
\hline \multirow{2}{*}{$\begin{array}{l}\mathrm{Na} \\
\mathrm{me}\end{array}$} & \multicolumn{2}{|c|}{$\begin{array}{l}\text { Blood pressure } \\
\text { received }\end{array}$} & \multirow{2}{*}{$\begin{array}{l}\text { Classificatio } \\
\text { n }\end{array}$} & \multirow{2}{*}{$\begin{array}{l}\text { Symptoms and } \\
\text { factors }\end{array}$} & \multirow{2}{*}{$\begin{array}{l}\text { Risk of } \\
\text { Hyperten } \\
\text { sion with } \\
\text { Certainty } \\
\text { factor }\end{array}$} \\
\hline & $\mathbf{S}$ & D & & & \\
\hline $\begin{array}{l}\text { Jam } \\
\text { il }\end{array}$ & 123 & 86 & $\begin{array}{l}\text { Pre- } \\
\text { Hypertensio } \\
\mathrm{n}\end{array}$ & $\begin{array}{l}\text { - Headache } \\
\text { - Nape Weight } \\
\text { - Heart } \\
\text { palpitations } \\
\text { - Coffee } \\
\text { consumption } \\
\text { - Stress } \\
\text { - Lack of } \\
\text { exercise }\end{array}$ & $\begin{array}{l}76.0 \% \\
\text { (True) }\end{array}$ \\
\hline
\end{tabular}
receive blood pressure values from blood pressure measuring devices and classify them based on the received blood pressure according to the knowledge that has been instilled (based on Table 2).

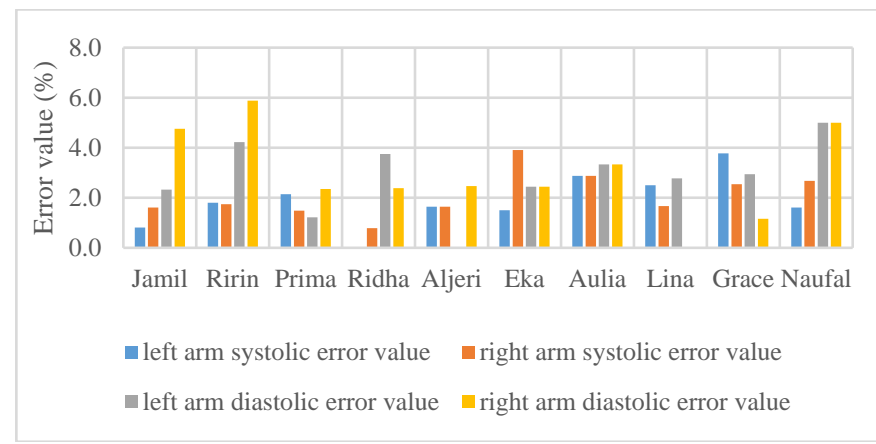

Fig. 7. Graph of Difference in Average Blood Pressure Testing Error on the Right Arm and Left Arm.

TABLE V. HYPERTENSION RISK TEST RESULTS 
TABLE VI. Results of BLOOd PRESSURe ClassificAtion TESTING AND THE EARLy DETECTION OF HyPERTENSION RISK LEVELS

\begin{tabular}{|c|c|c|c|c|c|c|}
\hline \multirow{2}{*}{ No } & \multirow{2}{*}{ Name } & \multicolumn{2}{|c|}{ Blood pressure received } & \multirow{2}{*}{ Classification } & \multirow{2}{*}{ Symptoms and factors } & \multirow{2}{*}{$\begin{array}{l}\text { Risk of } \\
\text { Hypertension with } \\
\text { Certainty factor } \\
\text { (True/False) }\end{array}$} \\
\hline & & $\mathbf{S}$ & D & & & \\
\hline 1 & Jamil & 123 & 86 & Pre-Hypertension & $\begin{array}{l}\text { - Headache } \\
\text { - Nape Weight } \\
\text { - Heart palpitations } \\
\text { - } \text { Coffee consumption } \\
\text { - Ltress } \\
\end{array}$ & $\begin{array}{l}76.0 \% \\
\text { (True) }\end{array}$ \\
\hline 2 & Ririn & 111 & 71 & Normal & $\begin{array}{l}\text { - Headach } \\
\text { - Impaired vision } \\
\text { - Consuming excess salt } \\
\text { - Consuming coffee } \\
\text { - Stress } \\
\text { - Lake of Exercise }\end{array}$ & $\begin{array}{l}76.0 \% \\
\text { (True) }\end{array}$ \\
\hline 3 & Prima & 140 & 82 & Pre-Hypertension & $\begin{array}{ll}\text { - } & \text { Consuming fatty foods } \\
\text { - } & \text { Consuming coffee } \\
\text { - } & \text { Stress } \\
\text { - } & \text { Lack of exercise } \\
\end{array}$ & $\begin{array}{l}52.0 \% \\
\text { (True) }\end{array}$ \\
\hline 4 & Ridha & 128 & 80 & Pre-Hypertension & $\begin{array}{ll}\text { - } & \text { Tired easily } \\
\text { - } \quad \text { Take Hypertension Drugs } \\
\text { - Diabetes Mellitus } \\
\text { Lack of exercise }\end{array}$ & $\begin{array}{l}96.46 \% \\
\text { (True) }\end{array}$ \\
\hline 5 & Aljeri & 122 & 79 & Normal & $\begin{array}{ll}\text { - } & \text { Tired easily } \\
\text { - } & \text { Consumption of Hypertension Drugs } \\
\text { - } & \text { Diabetes mellitus } \\
\end{array}$ & $\begin{array}{l}80.8 \% \\
\text { (True) }\end{array}$ \\
\hline 6 & Eka & 133 & 82 & Pre-Hypertension & $\begin{array}{ll}\text { - } & \text { Headache } \\
\text { - } & \text { Dizzy } \\
\text { - } & \text { Donsumption of Hypertes mellitus } \\
\text { - } & \text { Consumption of fatty foods } \\
\text { - } & \text { Lack of exercise } \\
\text { - } & \text { Have a family history of hypertension } \\
\end{array}$ & $\begin{array}{l}98.46 \% \\
\text { (True) }\end{array}$ \\
\hline 7 & Aulia & 139 & 90 & Pre-Hypertension & $\begin{array}{ll}\text { - } & \text { Headache } \\
\text { - } & \text { Undergo strenuous activity } \\
\text { - } & \text { Excessimption of fatty foods } \\
\text { - } & \text { Stress } \\
\text { - } & \text { Lack of exercise } \\
\text { - } & \text { Have a family history of hypertension } \\
\end{array}$ & $\begin{array}{l}80.8 \% \\
\text { (True) }\end{array}$ \\
\hline 8 & Lina & 120 & 72 & Normal & $\begin{array}{ll} & \text { Headache } \\
\text { - } & \text { Dizzy } \\
\text { - } & \text { Excessive Salt Consumption } \\
\end{array}$ & $\begin{array}{l}76.0 \% \\
\text { (True) }\end{array}$ \\
\hline 9 & Grace & 106 & 68 & Normal & $\begin{array}{ll}\text { - } & \text { Stress } \\
\text { - } & \text { Lack of exercise } \\
\end{array}$ & $\begin{array}{l}40.0 \% \\
\text { (True) } \\
\end{array}$ \\
\hline 10 & Naufal & 124 & 80 & Normal & $\begin{array}{ll}\text { - } & \text { Dizzy } \\
\text { - } & \text { Impaired vision } \\
\text { - } & \text { Smoker } \\
\text { - } & \text { Lack of exercise } \\
\end{array}$ & $\begin{array}{l}60.0 \% \\
\text { (True) }\end{array}$ \\
\hline
\end{tabular}


And the process of detecting the risk of hypertension continued with the selection of symptoms and risk factors of hypertension according to the user's experience. Meanwhile, the results of the detection were stored in a database and displayed on a smartphone (see Table 1). The percentage value of Hypertension Risk was obtained from the equation using the Certainty Factor method which was calculated based on the hypertension risk or the symptoms of hypertension by examined users. The results obtained from calculating the risk of hypertension with the certainty factor method, were manual system followed the results obtained from applications implanted on Android, and the success rate was $100 \%$. Therefore the built system using certainty factor methods could work properly and provide results as expected.

\section{CONCLUSION}

The system built for the blood pressure measurement process using MPX5500DP sensor was done by reading pressure changes on the arm cuff that wore by the user using the certainty factor method can give the following conclusions:

1) The certainty factor method is able to detect the risk of hypertension with the equation $\mathrm{CF}(\mathrm{n})=\mathrm{CF}(\mathrm{x})+\mathrm{CF}(\mathrm{y}) *(1-$ $\mathrm{CF}(\mathrm{x})$ ).

2) The Data hypertension risk detection contains in the Firebase Database Real-time displayed successfully on the smartphone.

3) The blood pressure testing gauges conducted on the right arm of 10 users produced an average error value of $2.092 \%$ on systolic value readings and $2.977 \%$ on diastolic values.

4) The blood pressure testing gauges conducted on the left arm of 10 users produced an average error value of $1,94 \%$ on systolic value readings and $2.8 \%$ on diastolic values.

5) The application of calculation hypertension risk implanted in android using the certainty factor method can give success results rate $100 \%$.

6) In the subsequent development of hypertension risk detection software, use different methods such as Machine Learning or other Decision Support System methods.

\section{REFERENCES}

[1] Badan Penelitian dan Pengembangan Kesehatan,. Riset Kesehatan Dasar 2018. Jakarta: "Kementerian Kesehatan Republik Indonesia", http://labdata.litbang.kemkes.go.id/images/download/laporan/RKD/2018 /Laporan_Nasional_RKD2018_FINAL.pdf [accessed on June, 19, 2021, 07.40 AM].

[2] Shikha Singh, Ravi Shankar, and Gyan Prakash Singh., "Prevalence and Associated Risk Factors of Hypertension: A Cross-Sectional Study in Urban Varanasi”, International Journal of Hypertension, 2017; 2017: 5491838, Published online 2017 Dec 3. doi: 10.1155/2017/5491838.

[3] N. M. Banki, S. L. Chan, V. A. Rao, R. B. Melles, and D. L. Bhatt, "Effect of Systolic and Diastolic Blood Pressure on Cardiovascular Outcomes," pp. 243-251, 2019, doi: 10.1056/NEJMoa1803180.

[4] M. M. M. P. H. C-phi, J. A. Osheroff, and B. R. Mph, "Improving Identification and Diagnosis of Hypertensive Patients Hiding in Plain Sight (HIPS) in Health Centers," Jt. Comm. J. Qual. Patient Saf., vol. 44, no. 3, pp. 117-129, 2018, doi: 10.1016/j.jcjq.2017.09.003.

[5] Mahnaz Ashoorkhani, Reza Majdzadeh, Jaleh Gholami, Hassan Eftekhar, and Ali Bozorgi, Understanding Non-Adherence to Treatment in Hypertension: A Qualitative Study, Int J Community Based Nurs
Midwifery. 2018 Oct; 6(4): 314-323., https://www.ncbi.nlm.nih.gov/ pmc/articles/PMC6226612/.

[6] J. Kitt, R. Fox, K. L. Tucker, R. J. Mcmanus, and K. L. Tucker, "New Approaches in Hypertension Management : a Review of Current and Developing Technologies and Their Potential Impact on Hypertension Care," 2019.

[7] Shikha Singh, Ravi Shankar, and Gyan Prakash Singh., "Prevalence and Associated Risk Factors of Hypertension: A Cross-Sectional Study in Urban Varanasi", International Journal of Hypertension, 2017; 2017: 5491838, Published online 2017 Dec 3. doi: 10.1155/2017/5491838.

[8] W. K. Bosu and D. K. Bosu, "Prevalence, awareness and control of hypertension in Ghana : A systematic review and meta-analysis". 2021.

[9] NICE Guideline, "Hypertension in adults: diagnosis and management", London: National Institute for Health and Care Excellence (UK); 2019 Aug, ISBN-13: 978-1-4731-3503-1.

[10] C. Update, "The Transition From Hypertension to Heart Failure," vol. 5, no. 8, 2017, doi: 10.1016/j.jchf.2017.04.012.

[11] E. Ku, B. J. Lee, J. Wei, and M. R. Weir, "Hypertension in CKD : Core Curriculum 2019," Am. J. Kidney Dis., vol. 74, no. 1, pp. 120-131, 2019, doi: 10.1053/j.ajkd.2018.12.044.

[12] Y. W. Kusumaningtyas, T. B. Indrato, M. P. A. T. P, and B. Utomo, "Digital Sphygmomanometer Based on Arduino Using TFT LCD Display," vol. 1, no. 1, pp. 34-38, 2019, doi: 10.35882/ijeeemi.v1i1.6.

[13] S. Definition, "Sphygmomanometer . Definition, How to Use Sphygmomanometer Definition Practice How To Use a Sphygmomanometer Procedures," pp. 1-3, 2021.

[14] O. Article, B. Shahbabu, A. Dasgupta, K. Sarkar, and S. K. Sahoo, "Which is More Accurate in Measuring the Blood Pressure ? A Digital or an Aneroid Sphygmomanometer," 2016, doi: 10.7860/JCDR/2016/ 14351.7458.

[15] F. Written, "Does High Blood Pressure Cause Headaches ?," pp. 1-11, 2021.

[16] W. H. O., "Who Technical Specifications for Automated Non-Invasive Blood Pressure Measuring Devices With Cuff Who Medical Device Technical Series", 2020, ISBN 978-92-4-000265-4 (electronic version), ISBN 978-92-4-000266-1 (print version).

[17] K. Santo et.al, "The Potential of mHealth Applications in Improving Resistant Hypertension Self-Assessment, Treatment and Control, National Library of Medichine", Curr Hypertens Rep . 2019 Oct 9;21(10):81. doi: 10.1007/s11906-019-0986-z.

[18] V. N. Shah and S. K. Garg, "Managing diabetes in the digital age," Clin. Diabetes Endocrinol., no. January, 2016, doi: 10.1186/s40842-0150016-2.

[19] J. R. White, "Evaluation and Evolution of Diabetes Mobile Applications : Key Factors for Health Care Professionals Seeking to Guide Patients," pp. 211-215, 2011.

[20] Nguyen, A. D. et al. "Mobile applications to enhance self-management of gout". International journal of medical informatics, 94, 2016, pp. 6774.

[21] M. Hardinge et al., "Using a mobile health application to support selfmanagement in chronic obstructive pulmonary disease : a six-month cohort study," BMC Med. Inform. Decis. Mak., pp. 1-10, 2015, doi: 10.1186/s12911-015-0171-5.

[22] Matthews, M. et al. "Development and evaluation of a smartphonebased measure of social rhythms for bipolar disorder". Assessment, 23(4), 2016, pp. 472-483. https://doi.org/10.1177/1073191116656794.

[23] D. Con and P. De Cruz, "Mobile Phone Apps for Inflammatory Bowel Disease Self-Management : A Systematic Assessment of Content and Tools," no. July 2019, 2016, doi: 10.2196/mhealth.4874.

[24] Feigin, V. et al., "Geomagnetic Storms Can Trigger Stroke: Evidence From 6 Large Population-Based Studies in Europe and Australasia, Stroke", 45(6), 2014, pp. 1639-1645 https://doi.org/10.1161/ STROKEAHA.113.004577.

[25] N. Kasabov et al., "Evolving spiking neural networks for personalised modelling, classification and prediction of spatio-temporal patterns with a case study on stroke," pp. 1-5, 2021. 
[26] Schuuring, M. J. et al. "Mobile health in adults with congenital heart disease: current use and future needs". Netherlands Heart Journal, 24(11), 2016 pp. 647-652. https://doi.org/10.1007/s12471-016-0901-z.

[27] Li, N. et al. "HHeal: A Personalized Health App for Flu Tracking and Prevention". In Proceedings of the 33rd Annual ACM Conference Extended Abstracts on Human Factors in Computing Systems, April 2015, pp. 1415-1420. https://doi.org/10.1145/2702613.2732804.

[28] N. C. Egejuru and P. A. Idowu, "Development of a Mobile-Based Hypertension Risk Monitoring System,” no. July, pp. 11-23, 2019, doi: 10.5815/ijieeb.2019.04.02.

[29] N. L. Fitriyani and M. Syafrudin, "Development of Disease Prediction Model Based on Ensemble Learning Approach for Diabetes and Hypertension," IEEE Access, vol. 7, pp. 144777-144789, 2019, doi: 10.1109/ACCESS.2019.2945129.

[30] Health Encyclopedia, "High Blood Pressure / Hypertension What is high blood pressure ?," pp. 1-9, 2021.

[31] J. S. Shahoud, T. Sanvictores, and N. R. Aeddula, "Physiology, Arterial Pressure Regulation," no. Cn Ix, pp. 4-7, 2021.

[32] R. Posts, "High blood pressure : The silent killer," pp. 19-21, 2021.

[33] M. C. Marketplace, "High blood pressure ( hypertension )."

[34] W. H. O., "Hypertension 17," no. May, pp. 4-7, 2021.

[35] T. R. Pressure, "Prehypertension : A Little Too Much Pressure , A Lot of Trouble What Do the Blood Pressure Numbers Mean ? Can You Help Control Your Blood," pp. 1-3, 2021.

[36] H. Blood and P. Guide, "Symptoms of Hypertension," pp. 1-18, 2021.

[37] A. E. Taylor et al., "Effect of Smoking on Blood Pressure and Resting Heart Rate," pp. 832-841, 2015, doi: 10.1161/CIRCGENETICS.115.001225.
[38] Sheila M. Hegde and Scott D. Solomon, Influence of Physical Activity on Hypertension and Cardiac Structure and Function, Curr Hypertens Rep. 2015 October ; 17(10): 77. doi:10.1007/s11906-015-0588-3.

[39] N. Rakova et al., "and decreases fluid intake Increased salt consumption induces body water conservation and decreases fluid intake," vol. 127, no. 5, pp. 1932-1943, 2017.

[40] W. H. O., "Salt reduction 29," no. April 2020, pp. 1-6, 2021.

[41] J. T. Section, "High Blood Pressure from Alcohol Consumption Need Help Now ?,” pp. 1-13, 2021.

[42] S. Ranabir and K. Reetu, "Stress and hormones Gonadal dysfunction," pp. 4-9, 2021.

[43] Prodia, Hypertension: The Oft-Ignored Cause of a Heart Attack. http://m.prodia.co.id/en/content/viewcontentsdetails/hipertensipenyebab-serangan-jantung-yang-sering. [accessed on June 20, 2021, 23:25 PM].

[44] Matthew R Alexander, et al, "What is the difference between primary ( essential ) and secondary hypertension (high blood pressure )?," p. 241381, 2021.

[45] E. M. Amoah, D. E. Okai, A. Manu, A. Laar, J. Akamah, and K. Torpey, "The Role of Lifestyle Factors in Controlling Blood Pressure among Hypertensive Patients in Two Health Facilities in Urban Ghana : A Cross-Sectional Study," vol. 2020, 2020.

[46] P. Verdecchia and F. Angeli, "The Seventh Report of the Joint National Committee on the Prevention, Detection , Evaluation , and Treatment of High Blood Pressure : The Weapons Are Ready,” pp. 843-847, 2003.

[47] A. Agusta, F. Y. Arini, and R. Arifudin, "Implementation of Fuzzy Logic Method and Certainty Factor for Diagnosis Expert System of Chronic Kidney Disease," vol. 2, no. April, pp. 61-68, 2020.

[48] A. S. Sembiring, O. Manahan, and M. Helentina, "Implementation of Certainty Factor Method for Expert System," 2019, doi: 10.1088/1742$6596 / 1255 / 1 / 012065$. 